\title{
Comparative Study Between Snodgrass and Urethral Advancement Methods in Repair of Distal Penile Hypospadias
}

\author{
Osama Al-Shahat ${ }^{1} \mathrm{MD}$, Tarek Zayid ${ }^{1} \mathrm{MD}$, Alnagaar Yassin ${ }^{1, *}$ MBBch
}

*Corresponding Author:

Yassin Alnagaar

dryassinreda1@gmail.com

Received for publication January 1, 2020; Accepted January 25, 2020; Published online January 31, 2020.

Copyright 2020 The Authors published by Al-Azhar

University, Faculty of

Medicine, Cairo, Egypt. All

rights reserved. This an open-

access article distributed under

the legal terms, where it is

permissible to download and

share the work provided it is

properly cited. The work

cannot be changed in any way

or used commercially.

doi: 10.21608/AIMJ.2020.69582

${ }^{1}$ Department of Plastic Surgery, Faculty of Medicine, Al-Azhar University, Cairo, Egypt.

\begin{abstract}
Background: Numerous original methods have been introduced to repair hypospadias with variable results.

Objective: The aim of this work is to evaluate the two techniques, Snodgrass and anterior urethral advancement for the repair of distal hypospadias.

Materials and Methods: A total of, 16 patients with distal hypospadias underwent primary repair in a prospective controlled randomized trial. Eight patients were allocated for a Snodgrass procedure and another 8 patients were allocated for a urethral advancement procedure.

A comparative study was conducted, and the outcome was evaluated in terms of satisfactory functional and cosmetic outcomes.

Results: The mean duration of surgery was significantly shorter for the Urethral advancement than for the Snodgrass procedure 56 minutes versus 76 minutes respectively.

The cosmetic and functional results were better in the urethral advancement than Snodgrass.

All patients healed uneventfully but one of the patients who underwent urethral advancement repair had chordee. One patient had a urethrocutaneous fistula and two patients had a failure of repair that occurred in the Snodgrass group.

Conclusion: Urethral advancement is a safer and more reliable modality for the primary repair of distal penile hypospadias. It has many

advantages, shorter operative time and better functional and cosmetic results.

Keywords: Hypospadias; Snodgrass; Anterior urethral advancement; repair
\end{abstract}

Disclosure: The authors have no financial interest to declare in relation to the content of this article. The Article Processing Charge was paid for by the authors

Authorship: All authors have a substantial contribution to the article

\section{INTRODUCTION}

Hypospadias is a common congenital anomaly of the penis with an incidence of about 1 in 300 lives male births. ${ }^{1}$ In a patient with hypospadias, dystopic meatus can occur at any level; however, the majority $(65-70 \%)$ is anterior, while about $30 \%$ is posterior in location. ${ }^{2}$ Advancing the urethra for hypospadias repair was first introduced in 1898 by Beck. However, this procedure was not consistently successful. The urethra was not mobilized sufficiently, and many patients had chordee. In 1977 Belman reported on a technique for hypospadias repair which involved wide urethral mobilization and advancement. ${ }^{3}$ Anterior urethral advancement as a one-stage technique for repair of hypospadias and urethral fistula is an excellent idea that was introduced by Ti-Sheng Chang in 1984 . He realized that the extent of urethral advancement after mobilization (in children up to 1.8 to $2 \mathrm{~cm}$ and in adult $4.5-5.0 \mathrm{~cm}$ ), was_sufficient to repair the penile variety of congenital hypospadias. ${ }^{4}$ In 1994, Snodgrass first reported the use of a tabularized incised plate (TIP) to repair distal hypospadias. Later, TIP has become mainstream internationally as the optimal surgical option. ${ }^{5}$ Any technique to repair distal hypospadias should be simple, easy, and could result in satisfactory functional and cosmetic outcomes. Despite continued refinement of numerous repair techniques, there is no satisfactory technique in terms of complications and cosmesis. ${ }^{6}$ This study aims to compare the most common two procedures for the repair of distal penile hypospadias as regard cosmetic and functional outcomes. 


\section{PATIENTS AND METHODS}

The two procedures for correcting distal hypospadias were assessed in a prospective randomized controlled study conducted in Al-Azhar University Hospitals between January 2019 and December 2019. Sixteen consecutive patients were divided randomly into 2 equal groups. In group A: Snodgrass procedure was performed. In group B: urethral advancement repair was done. The last case in both groups was done in May 2019, then patients were followed every week for 1 month then every 2 weeks for 2 months then monthly for the next three months to determine any complications and evaluate the cosmetic results.

Inclusion criteria: Patients aged from 1-12 y who had distal hypospadias (coronal or subcoronal) and all of them were primary cases (not operated before for hypospadias) with no chordee.

Exclusion criteria: Patients who had other associated anomalies as well as recurrent cases. Also, patients who had proximal hypospadias or had chordee.

The study was approved by the medical ethics committee of Al-Azhar University Hospitals and written informed consent was obtained from all patient's gardeners.

\section{Operative technique}

\section{Tabularized incised plate group (Snodgrass}

Technique)

- Placing a stay suture for traction of the penis, Catheterization, Tourniquet.

- Parallel longitudinal incisions at edges of the urethral plate were made to create glans wings and a midline incision was made in the urethral plate. (Figure 1)

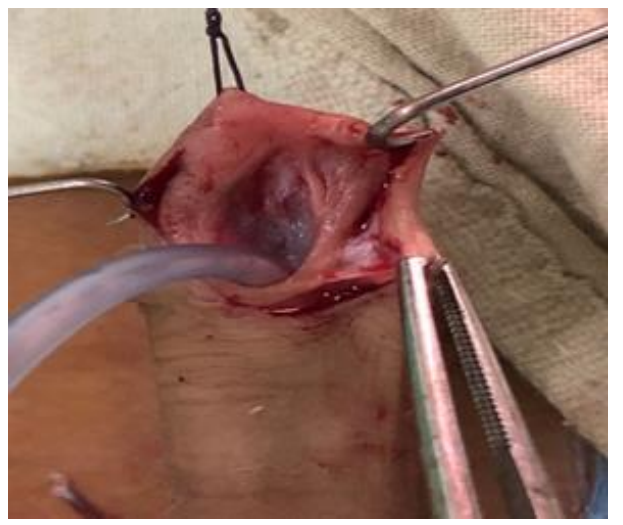

Fig.1: Incision of urethral plate and creation of urethral wings

- The urethral plate is tabularized with a two-layer and dartos fascia pedicle flap transposed ventrally to cover the entire neourethra. (Figure 2)

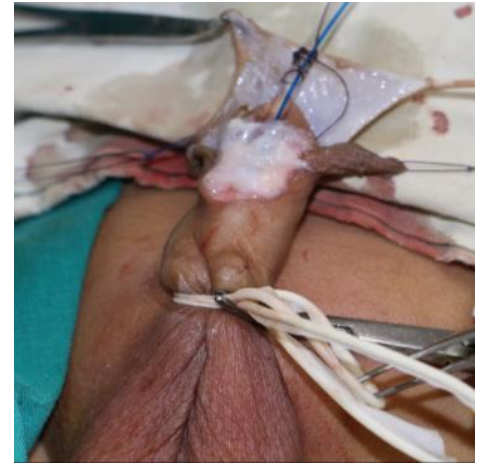

Fig.2: Dartos fascia pedicle flap transposed ventrally to cover the suture line of the tube

- Meticulous hemostasis and Closure of skin were done. (Figure 3)

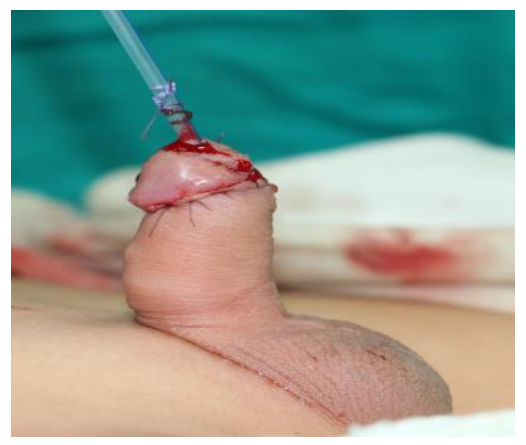

Fig.3: Meticulous hemostasis and closure of the skin

Urethral advancement group:

- Placing a stay suture, Catheterization, Tourniquet. - A circular incision with skin about $0.5 \mathrm{~cm}$ diameter around hypospadias meatus in the volar aspect of the penis was made to dissect and release the urethra.

- A small transverse incision about $0.5 \mathrm{~cm}$ at the volar aspect of the root of the penis was made to dissect and release the urethra distally. (Figure 4)

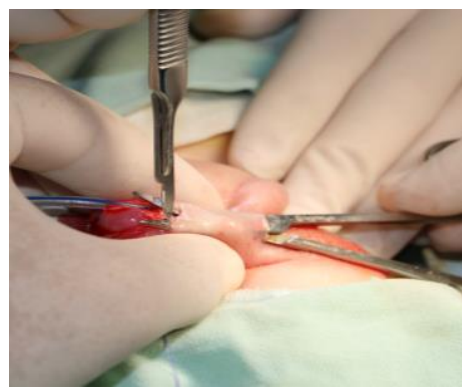

Fig.4: Proximal to distal release of the urethra from ventral aspect by blunt dissection 
- Dissection and complete release of the urethra was done. (Figure 5)

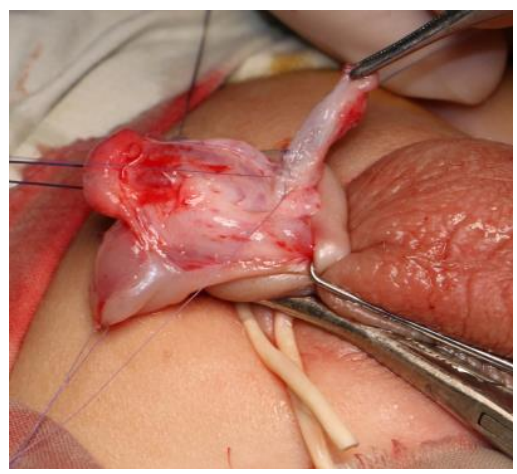

Fig.5: Complete release of the urethra

-Tunneling in the glans to pull out the urethra through it after catheter removal was done. (Figure 6)

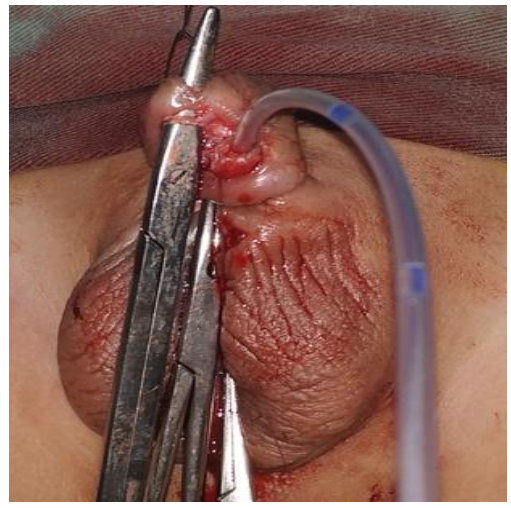

Fig.6: Patulus tunnel in the glans for urethral tunneling

- Suturing the meatus at the tip of the glans after reinsertion of the catheter was done. (Figure 7) -Lastly, closure of the wound and insertion of a small drain was done

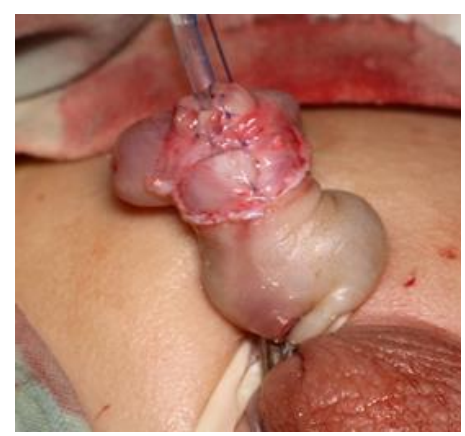

Fig.7: Suturing the meatus at the tip after urethral tunneling

\section{Statistical Analysis}

Data were analyzed using Statistical Program for Social Science (SPSS)version 24. Quantitative data were expressed as mean \pm standard deviation (SD). Qualitative data were expressed as frequency and percentage.

The following tests were done:

Independent-samples t-test of significance was used when comparing two means.

Mann-Whitney U test was used when comparing two means (for abnormally distributed data).

Chi-square test: was used when comparing nonparametric data.

Probability (P-value)

-P-value $<0.05$ was considered significant.

-P-value $<0.001$ was considered as highly significant.

-P-value > 0.05 was considered insignificant.

\section{RESULTS}

Sixteen patients with distal hypospadias underwent primary repair. Eight of them were allocated for a Snodgrass procedure and their age ranged between 12 months to 9 years (Mean \pm SD $3.6 \pm 2.5$ ). Urethral advancement repair was carried out for the other eight patients and their age ranged between 12 months to 12 years. (Mean \pm SD 3.2 \pm 3 .2). The mean follow-up period in both groups was 7 months (ranged between 6 months to12 m).

The mean operative duration was significantly less for the urethral advancement than for the Snodgrass technique. It was $56.9 \pm 7.5 \mathrm{~min}$. and $76.9 \pm 10.3 \mathrm{~min}$ respectively. (p-value was significant) as shown in Table 1.

\begin{tabular}{|c|c|c|c|c|c|}
\hline & & $\begin{array}{c}\text { Group I } \\
(\mathrm{N}=8)\end{array}$ & $\begin{array}{c}\text { Group II } \\
\qquad(\mathrm{N}=8)\end{array}$ & test & P-value \\
\hline $\begin{array}{l}\text { Operative time by } \\
\text { minuets }\end{array}$ & $\begin{array}{c}\text { Mean } \pm \text { SD } \\
\text { Range }\end{array}$ & $\begin{array}{c}76.9 \pm 10.3 \\
60-90\end{array}$ & $\begin{array}{c}56.9 \pm 7.5 \\
50-70\end{array}$ & $\mathrm{~T}=4.4$ & $0.001 \mathrm{~S}$ \\
\hline \multirow{2}{*}{$\begin{array}{c}\text { Postoperative } \\
\text { hospital stays and } \\
\text { catheter removal } \\
\text { by days }\end{array}$} & Mean \pm SD & \multirow{2}{*}{$\begin{array}{c}6.6 \pm 0.7 \\
5-7\end{array}$} & \multirow{2}{*}{$\begin{array}{c}2.4 \pm 1.06 \\
2-5\end{array}$} & \multirow[b]{2}{*}{$\begin{array}{c}\mathrm{MW}= \\
0.5\end{array}$} & \multirow[b]{2}{*}{$\begin{array}{c}<0.001 \\
\text { HS }\end{array}$} \\
\hline & Range & & & & \\
\hline \multirow{2}{*}{$\begin{array}{l}\text { Intra-operative } \\
\text { complications }\end{array}$} & No & $100 \%$ & $87.5 \%$ & \multirow{2}{*}{$\begin{array}{l}\mathrm{X}^{2}= \\
1.07\end{array}$} & \multirow[b]{2}{*}{$0.302 \mathrm{NS}$} \\
\hline & $\begin{array}{l}\text { Urethral } \\
\text { Inj. }\end{array}$ & $0 \quad 0 \%$ & $12.5 \%$ & & \\
\hline
\end{tabular}

Table 1: Comparison between studied groups as regard operative data

\section{In Snodgrass group}

All patients discharged on $5^{\text {th }}$ to $7^{\text {th }}$ postoperative day after catheter removal (Mean \pm SD $6.6 \pm 0.7$ ).

No intraoperative complications occurred but as regards postoperative complications, dysuria occurred in one patient which was responded to analgesics and regular frequent dilatation of meatus by a thermometer with lubricant. Wound inflammation occurred in one patient that responded to frequent dressing and antibiotic. Urethrocutaneous fistula occurred in one patient which managed by frequent dilatation of meatus by a thermometer or Nelaton catheter (size 8 F) with lubricant then spontaneous closure occurred. Failure of repair occurred in two patients. 
None of the patients exhibited hematoma, retention of urine, penile torsion catheter slippage or catheter blockage.

Meatal stenosis occurred in one patient which managed by regular dilatation of the external urethral meatus by a sterile thermometer twice daily for 3 weeks and the problem was resolved. The urinary stream was straight in 6 patients.

Parent satisfaction was good in 4 cases, fair in 2 cases and poor satisfaction in 2 cases.

\section{In urethral advancement group}

All patients discharged in $2^{\text {nd }}$ postoperative day after catheter removal except one patient discharged in the $5^{\text {th }}$ postoperative day (who had a urethral injury).

Two intraoperative complications occurred. One patient had a urethral injury, in which we continued urethral advancement after urethral repair and coverage by dartos fascia flap and the other one had a corporal injury that was directly repaired. (Figure 8 and Figure 9).

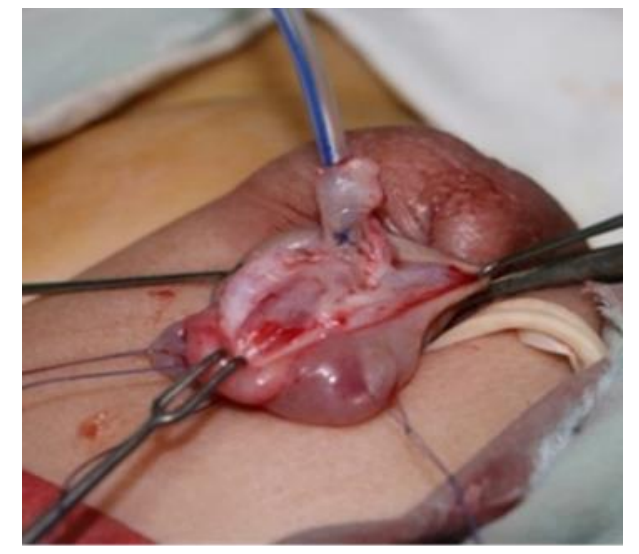

Fig.8: Urethral injury during dissection

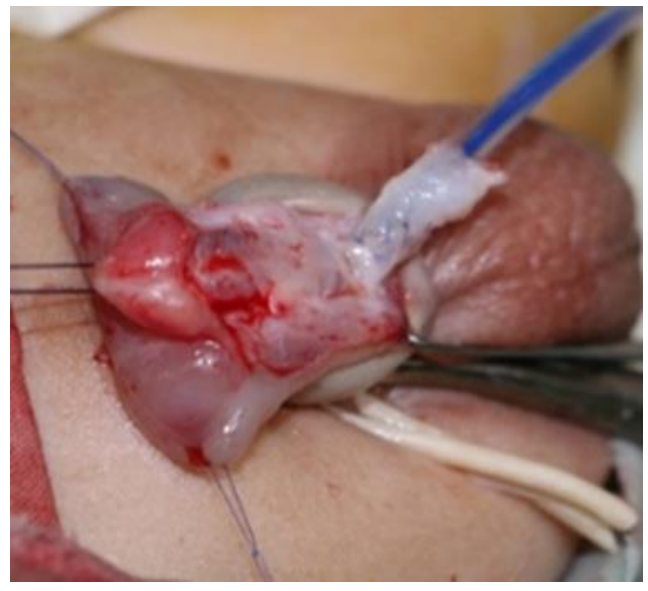

Fig. 9: Urethral repair by vicryl 5/0

Early postoperative complications were edema of glans that occurred in 2 patients which resolved spontaneously. Bleeding occurred in one patient in $3^{\text {rd }}$ postoperative day outside the hospital which managed by compression and blood transfusion.

None of the patients exhibited dysuria, wound infection, urethrocutaneous fistula, retention of urine, penile torsion catheter slippage, catheter blockage or failure of repair.

As regard late postoperative complications, chordee occurred in one patient in which corrected by dorsal plication later, after 6 months.

None of the patients exhibited meatal retraction, urethral stricture, urethral diverticulum. The urinary stream was straight in all patients.

Parent satisfaction was good in 7 cases and fair in 1 case (in which bleeding occurred).

Aesthetic appearance: according to the HOPE scoring system, all patients had score 10 in all items (the position and shape of the meatus, shape of the glans, and penile skin as well as penile torsion and curvature) except one patient had score 7 in penile curvature. (Figure 10)

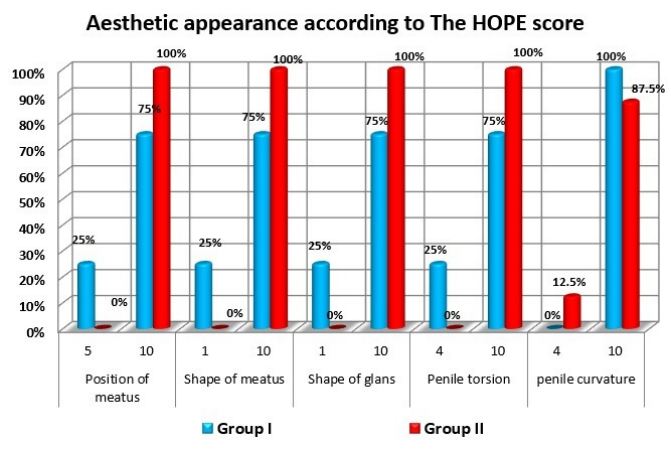

Fig.10: Comparison between studied groups as regard aesthetic appearance according to The HOPE score

\section{DISCUSSION}

Hypospadias continues to be a challenging problem for surgeons. The current operative concept in hypospadias surgery is based on a perfect singlestage repair of the malformation and should result in functional excellence and a cosmetically normal looking penis. ${ }^{8}$

Due to the presence of this plethora of techniques, Masterson et al. needed to mark a realistic goal and to follow a protocol to evolve a guideline on the management of hypospadias. ${ }^{9}$

This study aimed to choose a safe and reliable procedure for the primary repair of distal penile hypospadias.

In this study, the operative time of urethral advancement operation ranged from 50 to $70 \mathrm{~min}$, with a mean \pm SD time of $56.9 \pm 7.5 \mathrm{~min}$. while Elemen et al. ${ }^{10}$ reported a mean operation time of $58.82 \pm 22.87 \mathrm{~min}$, and Awad ${ }^{11}$ reported a mean operative time ranging from 30 to $50 \mathrm{~min}$, with an average of $45 \mathrm{~min}$.

In this study, one case had postoperative penile curvature, while Atala ${ }^{3}$, reported, among 73 patients, meatal retraction has occurred in two patients who required surgical correction.

In our study we removed the catheter after 2 days without any obvious complications, while Ekinci et al. ${ }^{12}$, Alkan et al. ${ }^{13}$, Atala ${ }^{3}$, Awad ${ }^{11}$ and Elemen et al. ${ }^{10}$ left the urethral catheter for a mean \pm SD duration of $2.3 \pm 0.5$ days, $4.64 \pm 1.07$ days, 1 day, 2 days, and $4.00 \pm 1.63$ days respectively. 
None of our patients developed urinary retention postoperatively while Awad ${ }^{11}$ reported that, among their 72 patients, postoperative urine retention occurred in seven $(9.7 \%)$ patients and one of them required bladder drainage.

In this study, one (12.5\%) patient had a small hematoma in glans at $3^{\text {rd }}$ day postoperative and was treated conservatively. None of our patients developed superficial wound infection.

Hassan et al. ${ }^{6}$ reported that, among their 30 patients, three cases had a postoperative hematoma (10\%), which were managed conservatively and resolved spontaneously. This nearly was similar to the incidence of hematoma in our study. Two $(6 \%)$ patients developed wound infection.

Paparel et al. ${ }^{14}$ reported that, among their 26 patients, four cases had postoperative bleeding (15\%) and one of them returned to the theatre to stop the bleeding. While Atala ${ }^{3}$, reported a single case of postoperative hematoma (1.3\%) among 73 patients. In contrast to Ekinci et al. ${ }^{12}$, who reported no early complications such as bleeding, hematoma and wound infection. In our study, one (12.5\%) patient had late postoperative complications (chordee) which corrected by dorsal plication 6 months later. None of our patients developed meatal stenosis, meatal retraction or fistula.

Hassan et al. ${ }^{6}$ reported that, among their 30 patients, three $(10 \%)$ patients developed meatal stenosis, two $(6 \%)$ of them responded to repeated dilatation twice weekly for 2 weeks and one (3\%) needed meatoplasty. There was no recurrent chordee. Two (6\%) patients underwent meatal retraction, where the urethra migrated proximally but still within the glans; only one of these patients required a second procedure. While Ekinci et al. ${ }^{12}$ reported that among a total of 171 patients, four $(2 \%)$ cases had meatal stenosis, four $(2 \%)$ cases had a fistula, four $(2 \%)$ cases had meatal regression and four $(2 \%)$ cases of granular dehiscence.

As regard Snodgrass operation:

In this study, the operative time ranges between 60 min. to $90 \mathrm{~min}$. (average $75 \mathrm{~min}$.) which is the same time reported by Oswald et al 2000. ${ }^{15}$

In this study, fistula formation occurred in one patient $(12.5 \%)$ and meatal stenosis occurred in another one patient $(12.5 \%)$ which resolved spontaneously by regular dilatation of meatus. That was in agreement with Elbakry ${ }^{16}$ who reported that postoperative regular urethral dilatation should be considered as an integral part of the TIP urethroplasty to prevent the neourethral and/or meatal stenosis with subsequent urethral fistula. Also, our study was in agreement with Borer et al. ${ }^{17}$ and Samuel \& Wilcox ${ }^{18}$ regarding using a vascularized pedicle flap to cover the urethral tube to minimize fistula formation.

In this study, the cosmetic appearance was satisfactory in 6 patients $(75 \%)$. The urinary stream was straight in 6 patients $(75 \%)$. Meatal stenosis was found in one patient $(12.5 \%)$ and fistula formations occurred in another one patient $(12.5 \%)$.

The results of O'Connor and Kiely ${ }^{19}$ were satisfactory regarding the cosmetic appearance in $97 \%$. The urinary stream was straight in $94 \%$. Meatal stenosis was found in $21 \%$ and fistula formations occurred in $3 \%$.
Holland et al. ${ }^{20}$ did a study for 59 patients with a mean age of 13 months, using the Snodgrass technique, and followed them for 9 months. Fistula and meatal stenosis were reported in $10 \%$, and $5 \%$ of cases respectively. Appearance and functional results were reported to be acceptable. While in our study there were 8 patients with wean age 30 months and follow up period was 7 months.

\section{CONCLUSION}

In this study, the Snodgrass operation was a more traumatic technique than urethral advancement operation. It needs an incision of the urethral plate and glanular wings, neourethra formation and the use of the dartos fascia as a barrier layer. All these steps are bloody and needed more operative time. While the urethral advancement operation technique needed only urethral dissection and tunneling of the glans after skin incision. Thus, in our study, we observed a significantly shorter operative time for urethral advancement operation

\section{REFERENCES}

1. Iqbal T, Nasir $U$ and Khan M. Frequency of complication in the Snodgrass repair and its risk factors. Pakistan Journal of Surgery. 2011;27(3):188-93.

2. Hammouda H, Hassan Y, Abdelateef A et al. New concepts in urethral advancement for anterior hypospadias. J Uro 2008; 4:286-289.

3. Atala A. Urethral mobilization and advancement for midshaft to distal hypospadias. The Journal of urology. 2002 Oct;168(4 Part 2):1738-41.

4. Chang T. Anterior urethral advancement: a onestage technique for hypospadias repair. British journal of plastic surgery. 1984 Oct 1;37(4):530-5.

5. Shuzhu C, Min W, Yidong L, et al. Selecting the right method for hypospadias repair to achieve optimal results for the primary situation. SpringerPlus. 2016 Dec;5(1):1624.

6. Hassan H, Almetaher H, Negm M, et al. Urethral mobilization and advancement for distal hypospadias. Annals of Pediatric Surgery. 2015;11(4):239-43.

7. van der Toorn, F, de JongT, de Gier, R, et al. Introducing the HOPE (Hypospadias Obective Penile Evaluation)-score: a validation study of an objective scoring system for evaluating cosmetic appearance in hypospadias patients. Journal of pediatric urology, $2013 \mathrm{Sep}$; 9(6), 1006-16.

8. Cooper C and Snyder H. Pediatric reconstructive surgery. Current opinion in urology. 2000 May $1 ; 10(3): 195-9$

9. Masterson J, Johnson H, Coleman G, et al. The development of microsurgical techniques in experimental and clinical repair of urethrocutaneous fistulas. The Journal of urology. 1982 Aug;128(2):285-6.

10. Elemen L and Tugay M. Limited urethral mobilization technique in distal hypospadias repair with satisfactory results. Balkan Medical Journal. 2012 Mar 1;2012(1):21-5.

11. Awad M. Urethral advancement technique for repair of distal penile hypospadias: A revisit. Indian J Plast Surg. 2006 Jan 1;39(1):34. 
12. Ekinci S, Çiftçi AÖ, Karnak İ, et al. Eccentric circummeatal based flap with limited urethral mobilization: an easy technique for distal hypospadias repair. Journal of pediatric urology. 2016 Apr 1;12(2):116-e1.

13. Alkan M, Oguzkurt P, Ezer S, et al. Evaluation of the results of the eccentric circummeatal-based flap with combined limited urethral mobilization technique for distal hypospadias repair. Journal of Pediatric Urology. 2008 Jun 1;4(3):206-9.

14. Paparel P, Mure P, Garignon Cet al. Koff's urethral mobilization: report of 26 hypospadias presenting a distal division of the corpus spongiosum. Progres en Urologie 2001 Dec;11(6):1327-30.

15. Oswald J, Körner I, and Riccabona $M$. Comparison of the perimeatal-based flap (Mathieu) and the tubularized incised-plate urethroplasty (Snodgrass) in primary distal hypospadias. BJU international. $2000 \mathrm{Apr} ; 85(6): 725-7$.
16. Elbakry A. Further experience with the tubularized-incised urethral plate technique for hypospadias repair. BJU Int. 2002 Feb;89(3):2914.

17. Borer J, Bauer S, Peters C et al. Tubularized incised plate urethroplasty: expanded use in primary and repeat surgery for hypospadias. The Journal of Urology. $2001 \mathrm{Feb}$; 165(2):581-5.

18. Samuel $\mathrm{M}$ and Wilcox D. Tubularized incised plate urethroplasty for distal and proximal hypospadias. BJU INT. 2003 Nov;92(7):783-5.

19. O'Connor K and Kiely E. Lessons learned using Snodgrass hypospadias repair. Irish Journal of Medical Science. 2006 Mar 1;175(1):37-9.

20. Holland A and Smith G. Effect of the depth and width of the urethral plate on tubularized incised plate urethroplasty. The Journal of Urology. 2000 Aug;164(2):489-91. 